\title{
Bluetooth for White Tooth
}

\author{
${ }^{1}$ Kavitha Mahendran, ${ }^{2}$ Sathish Sundar, ${ }^{3}$ Shobana Shekar, ${ }^{4}$ Baskaran Kumarasamy, ${ }^{5}$ Aruna Raj
}

\section{ABSTRACT}

Dental caries is caused by a complex interplay of factors, with $\mathrm{pH}$ of the saliva playing a crucial role in initiating the carious process in the presence of cariogenic bacteria. It is the second most common infection in the world next only to common cold. So its prevention becomes very important and we have to devise newer effective strategies for the same. This article enlightens a proof of concept and working model of an indigenously developed wireless $\mathrm{pH}$ monitoring device which will be converted into a miniaturized version in future.

The micro $\mathrm{pH}$ meter facilitates long-term tooth surface $\mathrm{pH}$ monitoring and providing real-time feedback to the patients and dental experts. The $\mathrm{pH}$ meter sends signals to an external monitoring equipment via Bluetooth facility and warns the subject about the $\mathrm{pH}$ status of his saliva. After the reception of the warning, the subjects should use routine brushing and flossing or use a medicated chewing gum or rinse with a mouthwash. Extrapolating to the clinical environment, this novel dental device can control a global disease called caries, which causes a lot of financial burden and time-consuming restorative dental treatment to patients worldwide.

Clinical significance: Real-time devices that monitor the $\mathrm{pH}$ changes in the oral environment and alert the patient prompting them to adopt preventive measures will help in executing oral care services on a day-to-day basis, thereby averting the need for comprehensive oral procedures.

Keywords: Bluetooth, Critical $\mathrm{pH}$, Dental caries, Micro $\mathrm{pH}$ meter.

How to cite this article: Mahendran K, Sundar S, Shekar S, Kumarasamy B, Raj A. Bluetooth for White Tooth. J Oper Dent Endod 2017;2(2):61-64.

Source of support: Nil

Conflict of interest: None

\section{INTRODUCTION}

The sphere of medicine and dentistry has stepped into what is called as biomonitoring revolution. With the emerging technologies, it has been possible to constantly

\footnotetext{
${ }^{1}$ Professor and Head, ${ }^{2-4}$ Postgraduate Student, ${ }^{5}$ Associate Professor

${ }^{1-5}$ Department of Conservative Dentistry and Endodontics Tamil Nadu Government Dental College, Chennai, Tamil Nadu India

Corresponding Author: Shobana Shekar, Postgraduate Student Department of Conservative Dentistry and Endodontics, Tamil Nadu Government Dental College, Chennai, Tamil Nadu, India Phone: +919884194454, e-mail: drshobana.bds@gmail.com
}

monitor the variations in the homeostasis of the subject's milieu by remote sensing. Biomonitoring devices have seen vast developments since 1965 and have efficiently technologized the field of hospital health care and home care. Monitoring of pulse rate, heart beat (electrocardiogram), blood pressure, blood oxygenation (pulse oximeters), physical activity (calories consumed on treadmill), vascular compliance, and endoscopy are few arenas in hospital health care where biomonitoring devices have found a wide scope. ${ }^{1,2}$ This technology has made it possible to monitor the $\mathrm{pH}$ alterations in the saliva of the patients by using a biomonitoring device. ${ }^{3}$

Dental caries is an infectious microbiological disease of the teeth that results in localized dissolution and destruction of the calcified tissues. ${ }^{4}$ It is a pandemic and is the second most common infectious disease next to common cold. The main etiological factor is the acidproducing bacteria which lowers the $\mathrm{pH}$ of the tooth surface and when this drops below the so-called critical $\mathrm{pH}$ of 5.5, the tooth surface starts to demineralize leading to loss of calcium and phosphate ions. ${ }^{5}$ This $\mathrm{pH}$ fluctuates several times a day after a carbohydrate meal or drink, but normally will get reverted soon by the buffering action of saliva. But in caries susceptible individuals, this buffering will not take place and rapid demineralization occurs, leading to progressive demineralization, thereby leading to dental caries and early loss of all the teeth. Kolahi et $\mathrm{al}^{6}$ have already applied this technology in the field of orthodontics utilizing an electrically operated enzyme microbattery embedded in the gingiva that uses glucose in the cells as a biofuel to enhance orthodontic tooth movement. This biomonitoring device is based on a similar principle to detect $\mathrm{pH}$ changes in the subject's saliva. Thus, monitoring of intraoral $\mathrm{pH}$ constantly will help to reduce the development of dental caries by warning the subject of the changes that take place in the oral cavity on a real-time basis prompting them to resort to maintenance techniques and averting more complicated restorative procedures in the future.

\section{BACKGROUND}

The objective of this article is to construct and design a working model of a biomonitoring device based on the Biodontic hypothesis put forth by Kolahi and Fazlati. ${ }^{3}$ Wireless biomonitoring technology has been widely used in the sphere of medicine to monitor various biomedical parameters like blood pressure, heart rate, oxygen 
saturation, etc. ${ }^{1}$ Based on this hypothesis, a miniaturized device resembling a tooth node or tooth jewel can be adhesively bonded to the tooth which can monitor the $\mathrm{pH}$ changes taking place inside the oral cavity. ${ }^{3}$ This device acts as a biosensor and the technique is noninvasive in nature and the working is autonomous in nature.

This article includes the design, parts, and working of an autonomous $\mathrm{pH}$ monitoring wireless dental device which can be used intraorally like a tooth jewel and can detect $\mathrm{pH}$ changes in the saliva when it falls below the critical $\mathrm{pH}$ of 5.5 .

\section{Parts of the Device (Micro Model)}

This intraoral biosensor consists of three components: (a) A micro pH meter, (b) power supply, and (c) ultra-lowpower wireless communicating device. ${ }^{3}$

\section{Micro $\mathrm{pH}$ Meter}

The micro $\mathrm{pH}$ meter utilizes a microprocessor-based design with an accuracy of detecting $\mathrm{pH}$ changes up to 0.01 and an auto-buffering mechanism. ${ }^{3}$

\section{Power Supply}

This system is powered by an enzyme-based biological battery which is microsized, also known as a microfabricated biocatalytic fuel cell or enzymatic microbattery. This system makes use of organic compounds like formate or glucose which utilizes enzymes like formate dehydrogenase or glucose oxidase respectively, as the catalyst to generate electricity through the application of same power generation principles found in living organisms. ${ }^{6,7}$ The basic reaction for a functioning enzymatic biofuel cell is a complete circuit comprised of the cathodic and anodic enzyme reactions that release and trap electrons respectively (Fig. 1). Glucose oxidase has been very commonly used as an anodic enzyme due to its high stability at physiological pH of 7.2 and high turnover rates. Similarly, bilirubin oxidase is the corresponding cathodic enzyme mainly because of its high stability at physiological $\mathrm{pH}$. Microfabricated enzyme battery has been used as a power supply for microsurgery robots and artificial organs. ${ }^{8}$

Advances in micromachining techniques and nanobiocatalysis have allowed the fabrication of very small devices that can be implanted inside the human body. Various nanostructured conductive materials like mesoporous media, nanoparticles, fibers, and tubes can act as efficient hosts of enzyme immobilization which can improve the lifetime and power density of bioenzymatic fuel cells owing to their large surface area which increases the enzyme loading.

\section{Ultra-low-power Wireless Communicating Device (Bluetooth)}

Bluetooth technology has been used in this device because it is cost-effective, consumes less power, and owing to its robust design. ${ }^{9}$ Whenever the $\mathrm{pH}$ drops below a critical level set in the $\mathrm{pH}$ sensor, caution about the fall in $\mathrm{pH}$ can be sent to external devices. ${ }^{9}$ The external monitoring equipment can be a mobile phone or a hands-free heads, which receives the caution signal as an SMS along with the digital $\mathrm{pH}$ reading (Fig. 2). Bluetooth through access points and cellular networks provides connectivity to personal area networks, local area networks, and wide area networks. The Food and Drug Administration has already approved Bluetooth system for medical purposes. ${ }^{9}$

Bluetooth supports several security features for increased patient privacy and data protection. These features include a unique public address for each user, two secret keys, PIN and password combinations. Safety can be further increased by data encryption. The fast

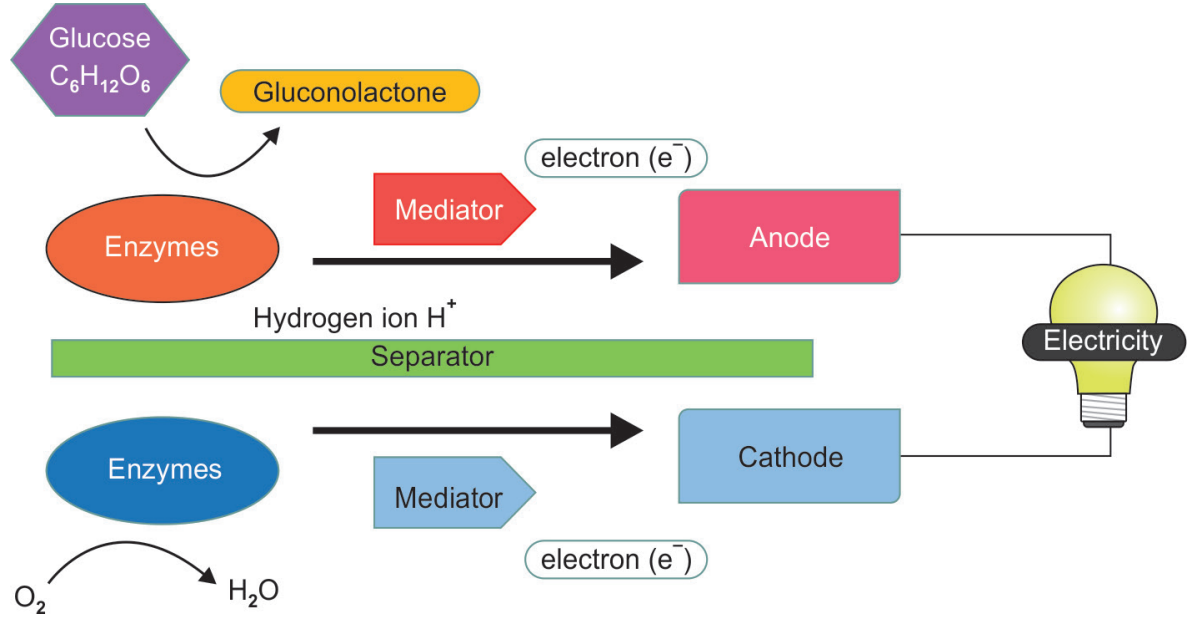

Fig. 1: Schematic representation for a simple glucose oxidase-based enzymatic biofuel cell 


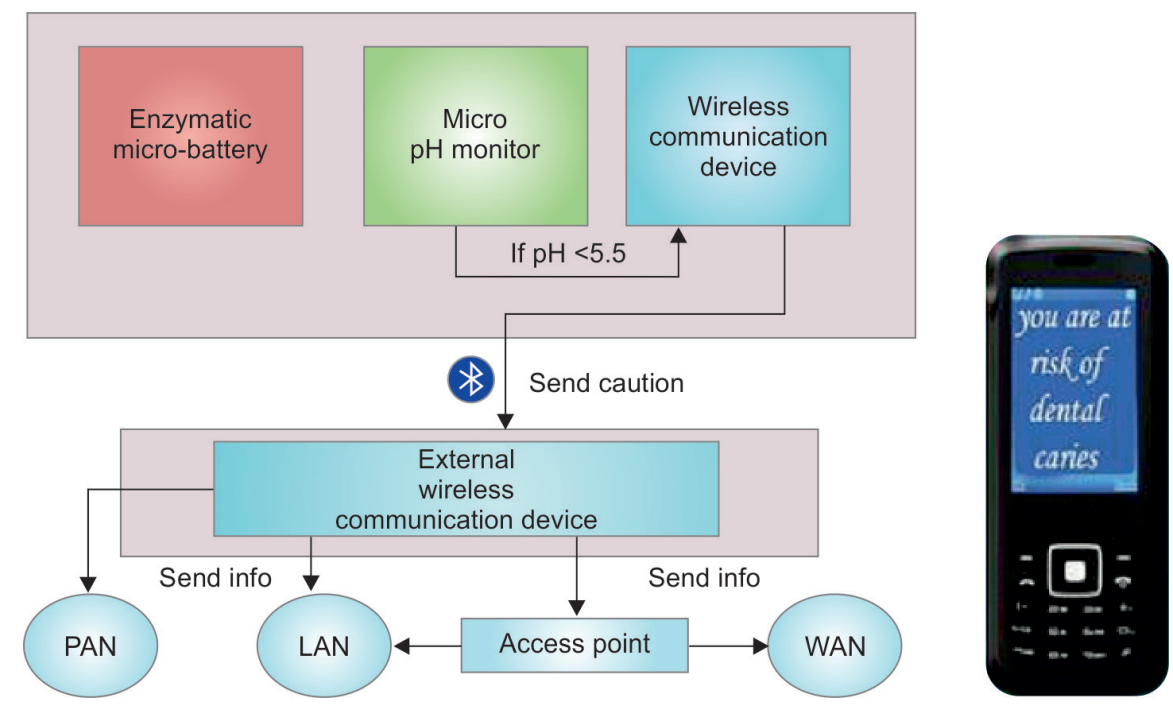

Fig. 2: Bluetooth sending caution signal to an external monitoring device; PAN: Personal area network; LAN: Local area network; WAN: Wide area network

frequency hopping spread spectrum provides additional safety by allowing only synchronized receivers to access the transmitted data. More security can be added at the application level if desired. Based on the above biodontic hypothesis proposed by Rossomando, ${ }^{10}$ we have designed a macro-sized Bluetooth device using the components already stated.

\section{Working of the Device (Macro Model)}

This model consists of a macro $\mathrm{pH}$ sensor connected to a $\mathrm{pH}$ indicating device which has a digital display. The $\mathrm{pH}$ indicator device has a subscriber identification module, i.e., connected to a wireless monitoring device. The wireless monitoring device can be any of the currently available electronic gadgets like laptops, tablets, or cell phones as in our model. The $\mathrm{pH}$ sensor detects the change in $\mathrm{pH}$ of the oral environment which in turn is transferred to the $\mathrm{pH}$ indicator which finally transmits the necessary $\mathrm{pH}$ detection changes to the external wireless device. Coke was used as the source of acid challenge (low $\mathrm{pH}$ solution) in our model. The $\mathrm{pH}$ sensor was wiped clean with a tissue paper prior to immersing it in the acidic challenge solution, i.e., a container of coke. The value of critical $\mathrm{pH}$ was set in the $\mathrm{pH}$ indicator device as 5.3. After immersion, the $\mathrm{pH}$ indicating device displays the drop in $\mathrm{pH}$ and when the $\mathrm{pH}$ drops below the critical value it sends signals to the external monitoring device, in our case the cell phone and the message displayed was "you are at risk of dental caries."

\section{DISCUSSION}

Literature is replete with articles and hypotheses that support biomonitoring devices and mobile applications that aid as self-motivating devices to caution the change in the subject's saliva. Though we have adequate scientific data in favor of these devices, very few attempts have been made to make these technical applications practically possible.

The CAMBRA (Caries Management By Risk Assessment) model was by Dean John D.B. Featherstone and colleagues at the UCSF School of Dentistry, is a reliable scientific procedure to assess caries (cavities) risk of the individual and to prevent further caries. Recently, Dr Peter Rechmann, Dr Richard Kinsel, and Dr Dean Featherstone have jointly designed MyCAMBRA—a new iOS app for iPhones and iPads. This mobile app enables dental professionals to quickly and easily assess a patient's caries risk. ${ }^{11}$ Health apps have been criticized for not inducing recognised behavior change techniques. ${ }^{12}$ Underwood et $\mathrm{al}^{13}$ conducted an online survey to assess the efficacy of Brush DJ oral health app, a smartphone app designed to motivate evidence-based oral hygiene routine. According to this survey, the mobile app proved to be a justifiable tool to promote an evidence-based oral hygiene routine.

The most important features of these apps would be to clearly and effectively communicate the ongoing oral changes to the patient and direct them to seek remedial measures to attend to their caries problem. Monitoring sensor can be placed in the most caries susceptible tooth surface according to the needs of the individual. The output from the sensor can be taken in any format like graphs, periodic values, or messages over any period of time. This helps us to evaluate the $\mathrm{pH}$ drop below critical level of the caries susceptible tooth. This will help us to modify the caries disease process or include treatment modifications as and when needed. After reception of the caution message, adequate preventive measures should be instituted at home like a medicated chewing gum with xylitol or chlorhexidine, fluoride mouth rinse 
or mouthwash, casein phosphopeptide-amorphous calcium phosphate remineralizing tooth mousse, fluoride dentifrice, etc. or the subjects can seek professional help.

These wireless devices can help in self-monitoring of patients' own $\mathrm{pH}$ levels. This model demonstrates a proof of concept and macromodel version of how latest technological advancements in wireless biomonitoring can be used in the prevention of dental caries.

\section{CONCLUSION}

This article is an attempt to deduce this hypothesis into the clinical environment and to assess the feasibility of such a device design. This macromodel has proven that it is possible to apply the Biodontic hypothesis into the clinical environment; with more technical assistance, a miniaturized version could be designed for clinical usage. Thus, intraoral noninvasive $\mathrm{pH}$ monitoring device can help prevent a pandemic disease called dental caries.

\section{REFERENCES}

1. Budinger TF. Biomonitoring with wireless communications. Annu Rev Biomed Eng 2003 Jan;5:383-412.

2. Saltzstein WE. Bluetooth: the future of wireless medical technology. Med Device Diagn Ind 2002 Feb;24(2):44.
3. Kolahi J, Fazilati M. Bluetooth technology for prevention of dental caries. Med Hypotheses 2009 Dec;73(6):1067-1068.

4. Southam, JC.; Soames, JV. Dental caries. 2nd ed. Oxford: Oxford University Press; 1993.

5. Lingström P, van Ruyven FO, van Houte J, Kent R. The pH of dental plaque in its relation to early enamel caries and dental plaque flora in humans. J Dent Res 2007 Feb;79(2): 770-777.

6. Kolahi J, Abrishami M, Davidovitch Z. Microfabricated biocatalytic fuel cells: a new approach to accelerating the orthodontic tooth movement. Med Hypotheses 2009 Sep;73(3):340-341.

7. Yeang K. Recharging your bio-batteries with a can of coke. Archit Design 2008 Mar-Apr;78(2):134-135.

8. Sasaki S, Karube I. The development of microfabricated biocatalytic fuel cells. Trends Biotechnol 1999 Feb;17(2):50-52.

9. Available from: www.pdacortex.com/fda.

10. Rossomando EF. Biodontics: dental students as change agents for dental school curricula. Compend Contin Educ Dent 2005 Aug;26(8):580-581.

11. Available from: www.MyCAMBRA.com.

12. Cowan LT, Van Wagenen SA, Brown BA, Hedin RJ, SeinoStephan Y, Hall PC, West JH. Apps of steel: are exercise apps providing consumers with realistic expectations?: a content analysis of exercise apps for presence of behavior change theory. Health Educ Behav 2013 Apr;40(2):133-139.

13. Underwood B, Birdsall J, Kay E. The use of a mobile app to motivate evidence-based oral hygiene behaviour. Brit Dent J 2015 Aug;219(4):E2. 